\title{
THE IMPACT OF MACROECONOMIC NEWS ON EXCHANGE RATE VOLATILITY*
}

\author{
HELINÄ LAAKKONEN \\ University of Jyväskylä, The School of Business and Economics, \\ P.O. Box 17, 00140 University of Helsinki, Finland, and FDPE; \\ e-mail:helina@cc.jyu.fi
}

\begin{abstract}
The impact of the US and European macroeconomic news on the USD/EUR volatility was examined by using the Flexible Fourier Form method. News increased volatility significantly, and the US news was the most important. The much-tested hypothesis of bad news having a greater impact on volatility was re-confirmed. The announcements were also divided into two categories, the first containing the news that gave conflicting information on the state of the economy and the other containing the news that were consistent. Conflicting news were found to increase volatility significantly more and faster than consistent news. (JEL: G14, C14, C12)
\end{abstract}

\section{Introduction}

According to the Triennal Central Bank Survey by the Bank for International Settlements, the daily turnover in the international foreign exchange markets was approximately 1800 billion US dollars in 2004 (BIS 2005). These markets are not only the biggest markets in the world, but they also keep growing very fast. In their earlier survey in 2001, BIS reported the volume of daily transactions to be 1200 billion US dollars, making the growth of these markets to be $36 \%$ with constant exchange rates (BIS 2005). The dynamics of foreign exchange markets have been examined a lot, but yet we know quite lit-

* I thank Markku Lanne and two unknown referees for constructive criticisms and helpful suggestions. I am grateful to Jouko Vilmunen for the possibility of collecting highfrequency data during my internship in the Research Department of the Bank of Finland. Geoffrey Wood and the participants of the Bank of Finland workshop and the Seminar in Economic Statistics in SSE are also gratefully acknowledged for the helpful comments. tle about these markets. The macro models are usually successful in explaining exchange rate dynamics in the long run, but explaining shortrun (a week or a few months) and very short-run (intraday) dynamics with these models has been very challenging (Meese and Rogoff 1983). From the viewpoint of these models it seems to be quite unclear what happens to the exchange rate in the short and very short run. In this context market microstructure models seem to work better and are more promising.

In this paper we study the connection between exchange rates and macro fundamentals in the short run by estimating the impact of macroeconomic announcements on USD/EUR exchange rate volatility. We use a new 5-minute frequency data set from 28 October 2003 to 20 January 2004 and estimate the impact of news with the Flexible Fourier Form method introduced by Andersen and Bollerslev in 1997. The announcements were collected from Bloomberg 
WECO (World economic calendar), and they are news of the macroeconomic fundamentals like GDP figures, interest rates and consumer confidence indexes. We study the effect between different groups of news and try to get new information of the asymmetries in the impact of different news categories.

The results suggest that news increase volatility significantly, the US news being the most important. Negative news seem to have a bigger effect than positive news, but more importantly, conflicting news increase the volatility more compared to consistent news. By conflicting news we mean the moments when more than one macro news were announced at the same time, and some of the figures were overestimated and some underestimated compared to the market forecast. Consistent news on the other hand means the moments when only either positive or negative news arrived to the markets. We also examine the effect of the news whose market forecast equals the announced figure and according to our results also this kind of so called "no-news" has a strong positive effect on volatility.

Many explanations for high (price) volatility in exchange rate markets have been proposed. Numerous theoretical and empirical models have highlighted important features of the market structure, which partly explain the dynamics of the foreign exchange markets. According to our results, the macroeconomic fundamentals are also one piece of the volatility puzzle. Because of the different motives of the heterogeneous agents (Farmer and Joshi 2002), different trading strategies (Admati and Pfleiderer 1988), psychological choices (Barberis et al. 1998) and different abilities to forecast and analyse the impact of the new information on the value of the exchange rates (Damodaran 1985), the new information does not only cause a jump in the exchange rate, but also higher volatility after the news.

The main finding of this empirical study is that it is the coherence of the signal that matters. When several macro figures are announced at the same time we could imagine that this would help the agents to get a broader picture of the state of the economy. However, this seems not to be the case if the agents do not get a clear positive or negative signal. If some figures are underestimated and some overestimated, it seems that the market agents have more difficulties in evaluating the effect of the news. This causes excess volatility to the exchange rates.

\section{The impact of macro announce ments on USD/EUR volatility}

\subsection{Earlier studies}

The empirical literature on the impact of news on exchange rate volatility has expanded greatly in recent decades. The earliest studies in the 1980s used daily return data and simple regressions, and did not get very promising results (Aggarwal and Schirm 1992). Since the 1990s the availability of high-frequency data, numerous variations of GARCH-models (Bollerslev et al. 1992), and the methods of filtering intraday volatility periodicity and other market anomalies (Andersen and Bollerslev 1997) have improved the analysis of the impact of news on exchange rate volatility.

The impact of news on exchange rate returns ${ }^{1}$ and the volatility of returns ${ }^{2}$ have been examined extensively. The most studied exchange rate has been DEM/USD, but also GBP/USD (for example Goodhart et al. 1993) and YEN/ USD (for example Melvin and Yin 2000) have been examined. Usually the news has been Reuter's headlines or scheduled macro announcements, but also the headlines of financial newspapers have been studied (for example, by Chan et al. 2001).

The results indicate that the news cause a jump in the level of the exchange rate, and increase the volatility of returns from an hour to two hours after the arrival of information (Andersen and Bollerslev 1998). The latest results of Evans and Lyons (2005) suggest, however, that the impact of news remains significant for several days. According to the earlier results, US news increase DEM/USD volatility more

\footnotetext{
${ }^{1}$ Almeida et al. (1998), Andersen et al. (2003), among others.

${ }^{2}$ Eddelbütten and McCurdy (1998), Melvin and Yin (2000), Chang and Taylor (2003), among others.
} 
than news from Germany and the impact of US news lasts longer than the impact of German news (Andersen et al. 2003).

Furthermore, the difference between the impact of positive and negative news has been studied. Negative news increase the volatility more than positive news (Andersen et al. 2003). Macroeconomic announcements have been examined also separately. The most significant announcement seems to be the monthly U.S. employment report. There have also been other significant announcements, for example the advanced report on the sales of durable goods and the merchandise trade. The most significant announcement from Germany has been the one concerning Bundesbank meetings (Andersen and Bollerslev 1998).

\subsection{The data}

The original data consists of one-minute frequency transaction price data of the USD/EUR exchange rate from Bloomberg. The observations are the prices of the first transactions in every minute and there are 84569 observations altogether. The period is from 28 October 2003 to 20 January 2004 . The global foreign exchange works 24 hours a day, but at weekends the markets are closed. Due to the lack of observations, the weekends were removed from the data from Friday midnight (GMT) to Sunday midnight. Also the New Year's Day was dropped due to the lack of observations. Christmas Day was another holiday when the market volume was low. In addition, volatility was much lower on Christmas Day. Since there were observations during 25 December, however, Christmas Day was not excluded from the data.

The one-minute frequency data was transformed to 5-minute data by picking up the price every five minutes starting from midnight. There were altogether 17195 observations and 60 days in the 5-minute data. If there were no transactions during the one-minute period, the observation was missing. There were 241 missing observations in the 5-minute data. They were replaced by the weighted average of the previous and following observations and the weight depended on how close those minutes were to the desired observation. The observations were missing usually around midnight (GMT), when the volume of the foreign exchange markets is at its lowest. There is also one longer period of missing observations in the data, which lasted 1.5 hours from 0:10 to 1:50 on 4 November $2003^{3}$. The missing observations were not replaced and the returns were set at zero.

The USD/EUR logarithmic return series from the period 28.10.2003-20.1.2004 is presented in Figure 1. The volatility around zero is very high and it lowers for awhile around the 12 $500^{\text {th }}$ observation, which indicates the lower volume markets on Christmas Day. Also small clusters can be noticed in the figure, which indicates the periodical intraday volatility. There are also big positive and negative jumps in the return series. There are no extremely big jumps first in one direction and then immediately after in the opposite direction, however, so it seems that there have not been any remarkable errors in the price series.

The biggest jump around the $15280^{\text {th }}$ observation indicates US macroeconomic news: five US macroeconomic figures were announced just five minutes before that jump. One of them was the unemployment rate in the US, which had decreased more than the markets had expected. The estimations were also made by excluding the biggest jump. This did not have an effect to the results.

\subsection{Intraday dynamics of volatility}

Various kinds of ARCH models have usually been considered the best for modelling the conditional heteroskedasticity of financial returns. However, when modelling the intraday returns, the ARCH models do not seem to work at all. This is due to the systematic periodical structure of volatility during the course of a day that ARCH models fail to consider.

To be able to investigate the intraday dynamics of the USD/EUR returns, the observations were divided into 5-minute intervals, totalling 288 in 24 hours. Absolute returns were used as

\footnotetext{
${ }^{3}$ The reason for missing observation period is unknown.
} 
Figure 1. USD/EUR 5-minute logarithmic returns

The figure graphs the five minute logarithmic returns of the USD/EUR exchange rate from the period 28 Oct 2003 to 20 Jan 2004

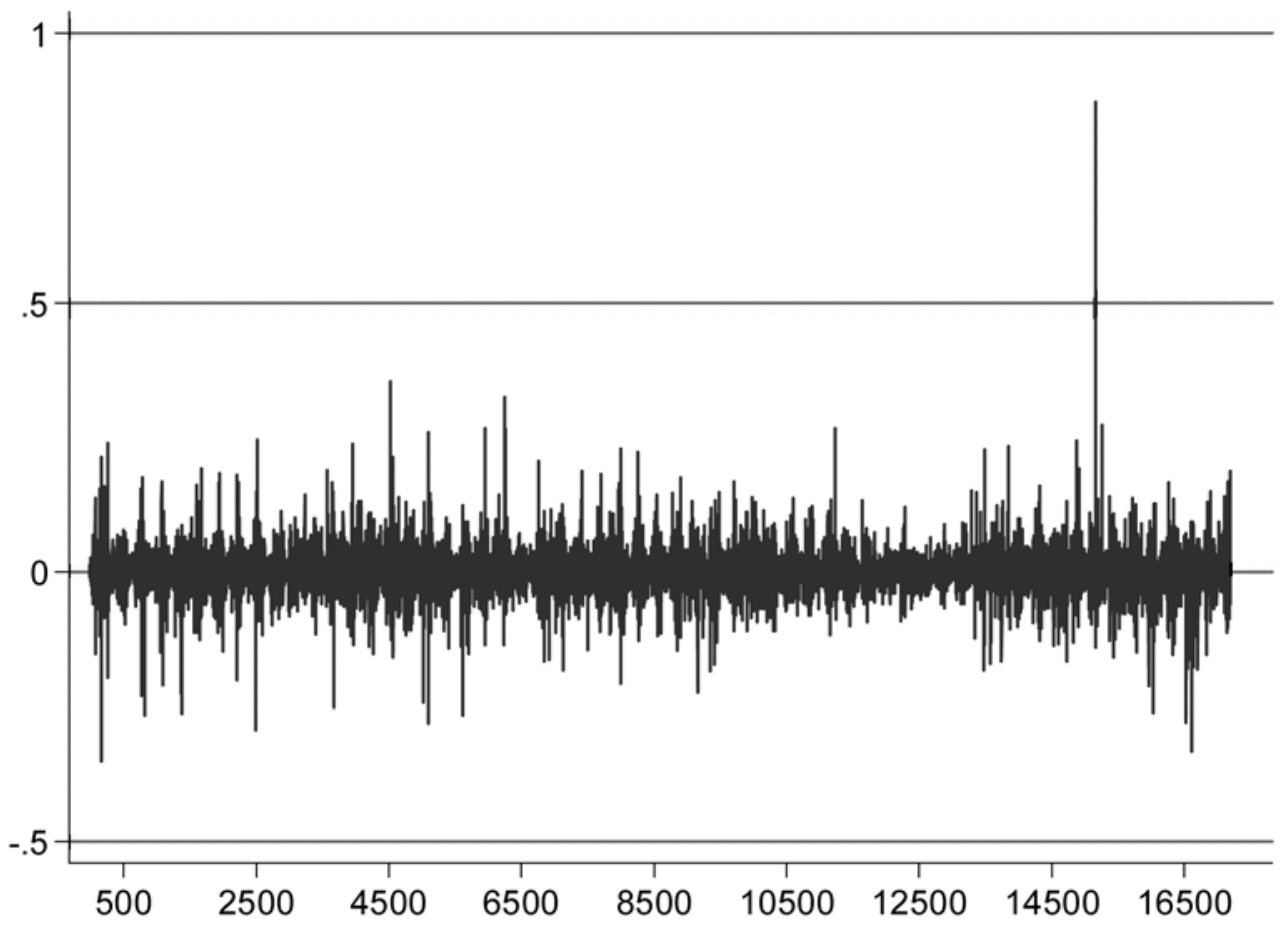

a measure of volatility. ${ }^{4}$ Figure 2 presents the average absolute returns of the 288 five-minute intervals. The intraday volatility structure, which depends on the time of day, can be seen in this figure. There is a big jump in the first interval due to the weekend breaks in the data. The returns between the closing price on Friday and the opening price on Monday might be very large. If we follow the schedules of the global foreign exchange market, we get the explanations for the levels of volatility in the different hours of the day. The Far East markets open around interval 12 (23:00 GMT) and this causes a small increase in the volatility. After this the

\footnotetext{
${ }^{4}$ Absolute returns have been used widely as a volatility measure in the literature. A literature review of the use of absolute returns is provided by Granger and Sin (1999) and the theoretical explanations are provided by Forsberg and Ghysels (2004). Absolute returns have also been used as a volatility measure in the news literature for example by Andersen and Bollerslev (1997), Andersen and Bollerslev (1998) and Andersen et al. (2003).
}

volatility decreases and is at its lowest around intervals 72 to 84 (04:00-06:00 GMT), when Hong Kong and Tokyo take their lunch hours. At 7:00 GMT (interval 108) the European market opens and that increases the volatility significantly. The volatility declines around interval 156 (11:00 GMT) because Europe is enjoying its lunch.

After interval 190 (14:00 GMT), when the US markets open and Europe has its most active hours, the volatility reaches its highest level. The volatility starts to decline slowly after interval 228 (17:00 GMT), when the European market closes. The volatility stays low until around midnight, when the Far East markets open up. The structure of volatility is consistent with other similar studies. The same periodicals are observed in a study by Andersen and Bollerslev (1997). The lunch hours of Tokyo and Hong Kong cause a bigger decline in volatility in their data, but other than that, the pattern is the same. Also the magnitude of the 
Figure 2. Average intraday volatility pattern

The figure graphs the mean absolute five minute return of USD/EUR during 288 five minute intervals ( 24 hours). Volatility pattern is caused by different trading times in the global foreign exchange markets.

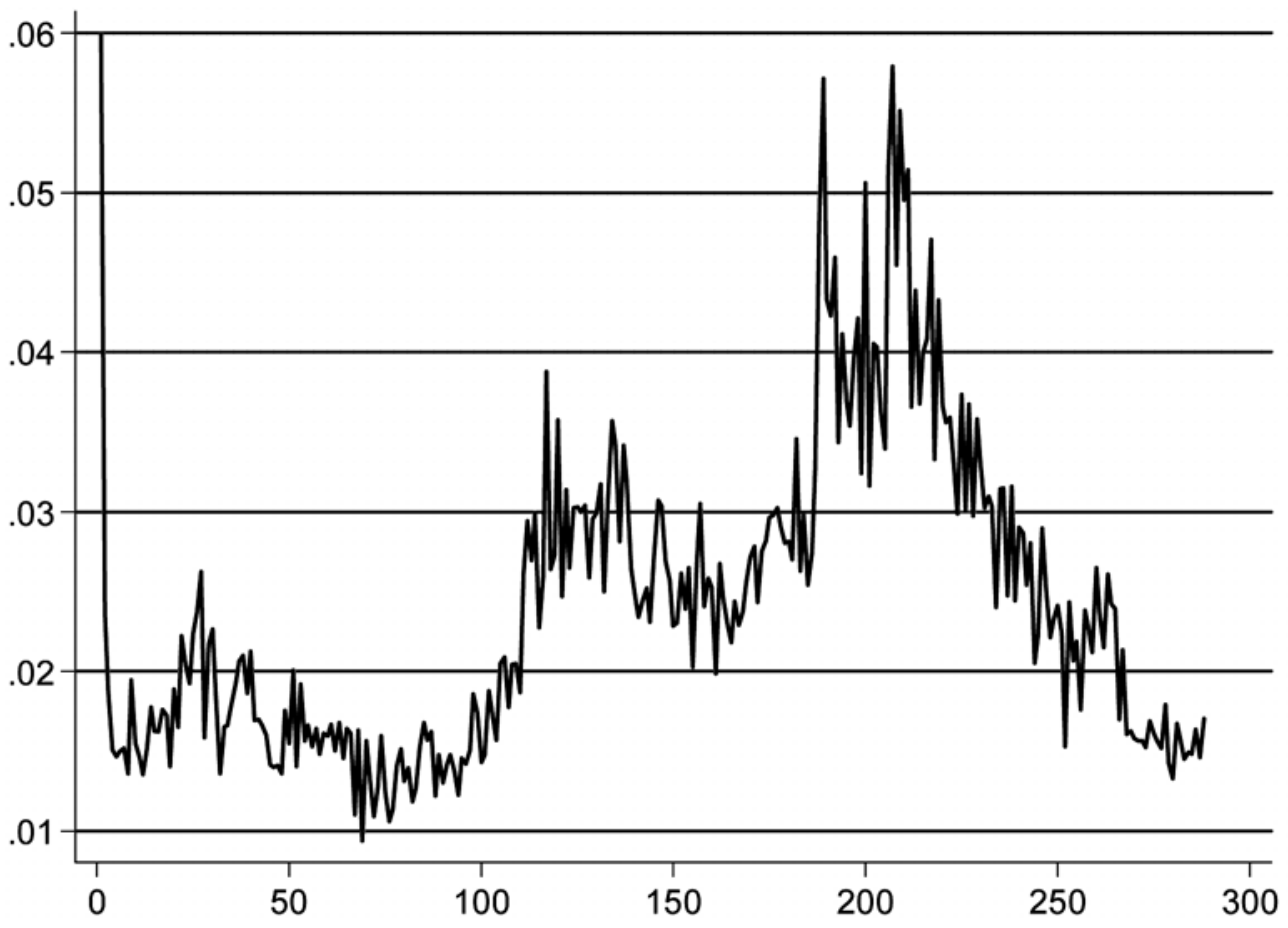

volatility is the same in this data as in the data of Andersen and Bollerslev. The lowest and the highest values of average volatility are 0.01 and 0.06 percent, respectively.

When this pattern is repeated every day, it causes a U-shape pattern in the autocorrelation of volatility. The autocorrelation coefficients of absolute returns represent the autocorrelation structure of return volatility. Figure 3 presents the autocorrelation coefficients of 288 fiveminute lags, i.e. the autocorrelogram for one day. The U-shape pattern can be clearly seen in the graph. If we draw the correlogram for 1500 lags, we get the autocorrelogram for five days (Figure 4). As can be seen, the U-shape pattern is repeated almost identically every day.

\subsection{Estimation method}

Andersen and Bollerslev (1997) developed a method based on Gallant's (1981) Flexible Fourier Form regression method to model the peri- odical intraday structure of volatility. The FFF method has recently become a standard method used in the studies that use high frequency data. ${ }^{5}$ Andersen and Bollerslev divided the volatility in the return process $R_{t, n}$ into three components: the daily volatility component $\sigma_{t}$ (divided by $N^{1 / 2}$ where the $N$ is the number of 5-minute intervals in 24 hours), the intraday volatility component $s_{t, n}$ and the random error term $Z_{t, n}$ (Equation 1). In the equation $n$ denotes the intraday interval and $t$ denotes the day.

(1) $R_{t, n}=E\left(R_{t, n}\right)+\frac{\sigma_{t}}{N^{1 / 2}} s_{t, n} Z_{t, n}$

Andersen and Bollerslev state that since the variability during the day is so systematic, the intraday dynamics of absolute returns can be

5 The FFF method is widely used in the news and intervention literature (see for example Andersen and Bollerslev (1998), Bollerslev et al. (2000), Cai et al. (2001) and Andersen et al. (2003)). 
Finnish Economic Papers 1/2007 - Helinä Laakkonen

Figure 3. Autocorrelation coefficients, 288 lags

The figure graphs the one day correlogram of the autocorrelation coefficients of the five minute absolute returns of the USD/EUR exchange rate. The shaded area graphs the Bartlett's MA(q) 95\% confidence bands.

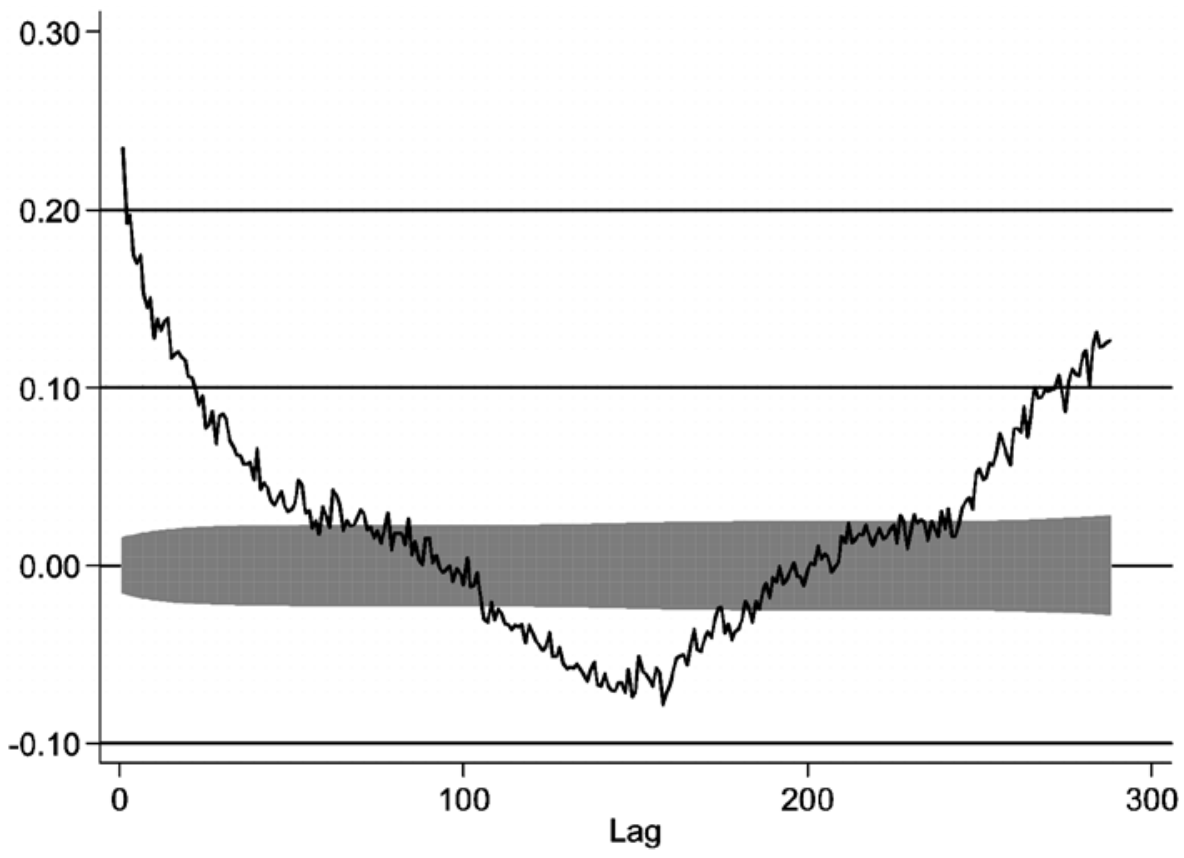

Figure 4. Autocorrelation coefficients, 1500 lags

The figure graphs the five day correlogram of the five minute USD/EUR absolute returns. The shaded area graphs the Bartlett's formula for MA(q) $95 \%$ confidence bands.

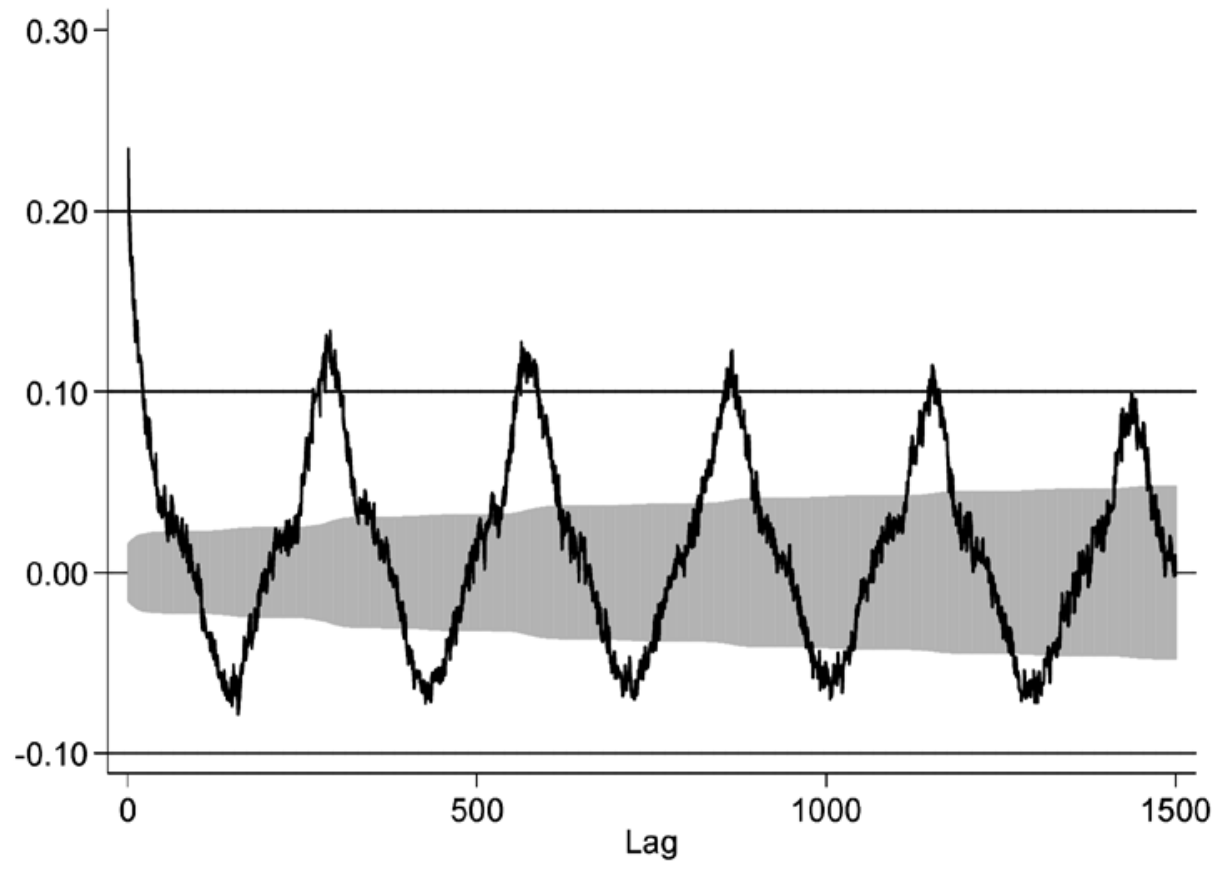


estimated by using the sine and cosine functions. They use the absolute returns as a measure of volatility $\left|R_{t, n}-\bar{R}\right|$, where the expected return is replaced by the mean return, and then eliminate the daily volatility component by dividing the volatility measure with $\hat{\sigma}_{t} / N^{1 / 2}$, where $\hat{\sigma}_{t}$ is the $\operatorname{GARCH}(1,1)$ model estimate for daily volatility and is $N$ the number of intervals in one day (288 in 5 minute, 24 hours markets).

After elimination of the daily component, squaring and taking logs, there are two components left on the right-hand side of the equation 1. The first is the component for the intraday volatility which can be modelled using the trigonometric functions and the other component is the error term, which includes the extra volatility of the markets, for example the volatility caused by new information.

$$
\begin{aligned}
f\left(\theta ; \sigma_{t}, n\right) & =\left[c+\sum_{k=1}^{D} \lambda_{k} I_{k}(t, n)+\delta_{1} \frac{n}{N_{l}}+\delta_{2} \frac{n^{2}}{N_{2}}\right. \\
& +\sum_{p=1}^{p}\left(\delta_{c, p} \cos \frac{p 2 \pi}{N} n\right. \\
& \left.\left.+\delta_{s, p} \sin \frac{p 2 \pi}{N} n\right)\right]+\varepsilon_{t, n}{ }^{6}
\end{aligned}
$$

where $f\left(\theta ; \sigma_{t}, n\right)=2 \ln \frac{\left|R_{t, n}-\bar{R}\right|}{\hat{\sigma}_{t} / N^{1 / 2}}$.

In the model (equation 2) $c$ is the constant, $N_{1}=(N+1) / 2$ and $N_{2}=(N+1)(N+2) / 6$ are normalizing constants, sine and cosine variables are for the capturing of intraday periodicity, $I_{k}$ are the indicator variables, which can be used for inserting day-of-the-week dummies or macro news into the model.

Filtering increases volatility during the low volatility periods of the day and decreases volatility during the high volatility periods. The intraday seasonality of the volatility is divided away, but other than that the returns remain the same. $^{7}$

\footnotetext{
${ }^{6}$ According to the Akaike and Schwartz Information Criteria the model with $p=9$ gives the best fit in this data set. We considered values of $p$ from 1 to 10 .

7 For details of the FFF approach, see Andersen and Bollerslev (1997).
}

Chang, Taylor and Martens (2002) compared different methods of modelling intraday volatility. They also compared how the different methods affect the forecasting power of GARCH models. According to their results, the FFF method is very suitable for filtering the intraday volatility. Figure 5 presents the five-day autocorrelogram of raw and filtered absolute returns. As we can see, the filtered absolute returns do not have systematic periodicity in the autocorrelation structure. Figure 6 presents the average absolute returns compared to the estimated fitted values we get from the Flexible Fourier Form equation. We can see that the model is capable of capturing the average volatility pattern quite satisfactorily.

\subsection{Descriptive statistics of the raw and filtered returns}

The key statistical figures of the raw and filtered return series are presented in Table 1 and the Figures 7 and 8 graph the distributions of the raw and filtered return series. The mean of the return series did not change when the returns were filtered. Mean return was in both of the series around 0.0004 , positive, but statistically not greater than zero. There are also no major changes in mean absolute returns caused by filtering. The mean absolute return fell slightly from 0.024 to 0.022 . Also the standard deviation did not change very dramatically. It only fell from 0.037 to 0.031 .

However, the filtering did have some effect on the statistical figures. The distribution of financial return series usually has a lot of extra kurtosis compared to the normal distribution, which indicates that there are more large returns compared to the tails of the normal distribution. The distribution of the USD/EUR returns was also skewed to the positive side, which indicates that there have been more big positive jumps than big negative jumps. Compared to the raw return series, the distribution of the filtered return series was closer to the normal distribution. The distribution of the filtered returns is more symmetric than the distribution of the raw returns. The skewness fell from 0.80 to 0.11 . Also the extra kurtosis of the distribution fell from 26.4 to 7.80 . Even though the distribution is 
Finnish Economic Papers 1/2007 - Helinä Laakkonen

Figure 5. Autocorrelation coefficients of the original and filtered returns

The figure graphs the five day correlogram of the filtered five minute absolute USD/EUR returns compared to original absolute returns. The returns have been filtered with the Flexible Fourier Form method that uses the sine and cosine functions to capture the cyclical pattern.

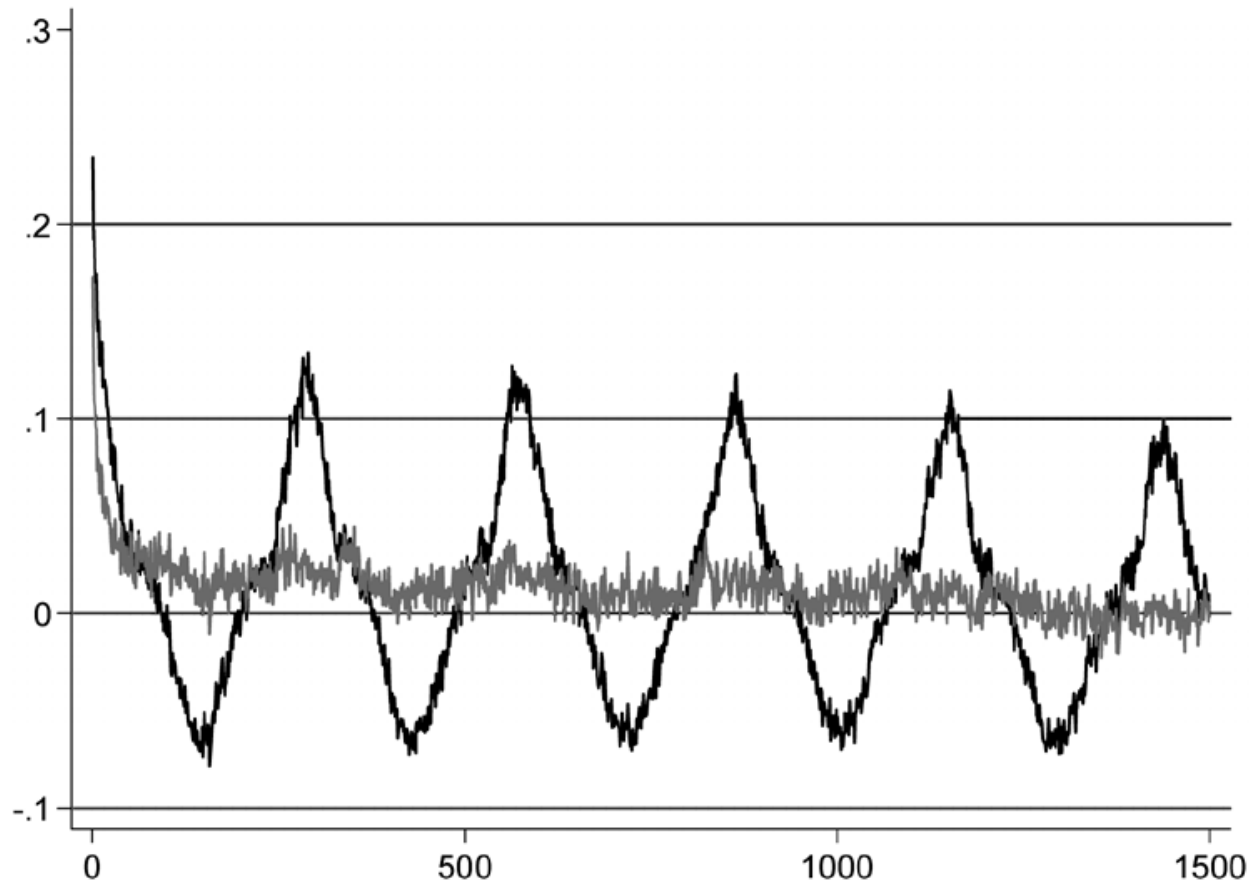

Figure 6 . The intraday volatility pattern compared to the estimated volatility

The gray line presents the mean absolute five minute USD/EUR return during 288 five minute intervals i.e. 24 hours. The dashed line is the volatility estimate from the Flexible Fourier Form model.

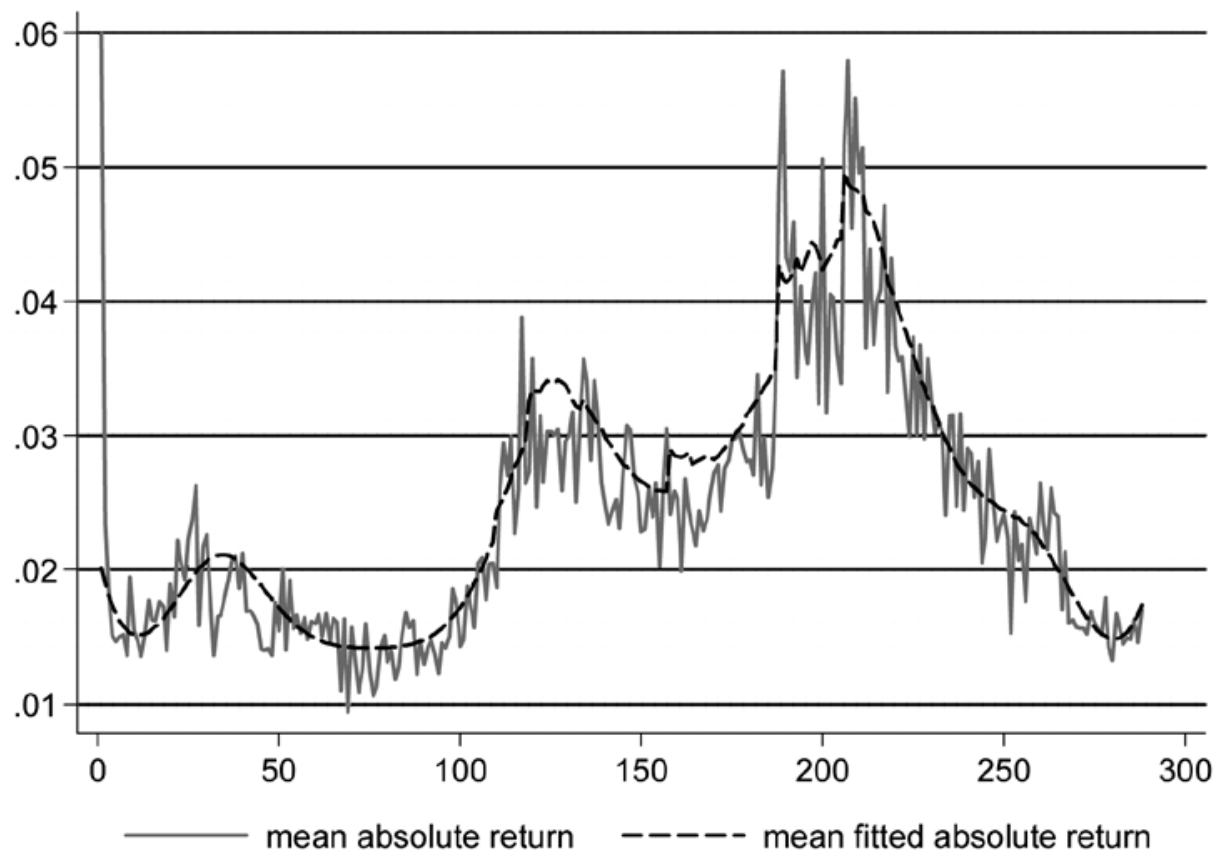


Table 1.

Key statistical figures

Table presents the key statistical figures of raw and filtered five minute logarithmic return series of USD/EUR exchange rate from the period 28.10.2003-20.1.2004. The intraday returns were filtered with the Flexible Fourier Form method.

\begin{tabular}{lcc}
\hline Key Statistical Figures & Returns & Filtered Returns \\
\hline Observations & 17195 & 17195 \\
Mean return & 0.00046 & 0.00038 \\
Mean absolute return & 0.024 & 0.022 \\
Mean absolute return 5 minutes before news announcements & 0.029 & \\
Mean absolute return 5 minutes after news announcements & 0.042 & 0.031 \\
Standard deviation & 0.037 & 0.11 \\
Skewness & 0.80 & 0.016 \\
Quartile skewness* & 0.0079 & 7.8 \\
Kurtosis & 26.4 & -0.32 \\
Minimum & -0.35 & 0.42 \\
Maximum & 0.87 & \\
\hline
\end{tabular}

* Bowley coefficient for skewness is defined as $Q S=\frac{\left(Q_{75}-Q_{50}\right)\left(Q_{50}-Q_{25}\right)}{\left(Q_{75}-Q_{25}\right)}$. This alternative measure of skewness based on the quartiles is not so sensitive for the outliers in the data (Moors et al. 1996).

Figure 7. Distribution of the five-minute logarithmic USD/EUR returns

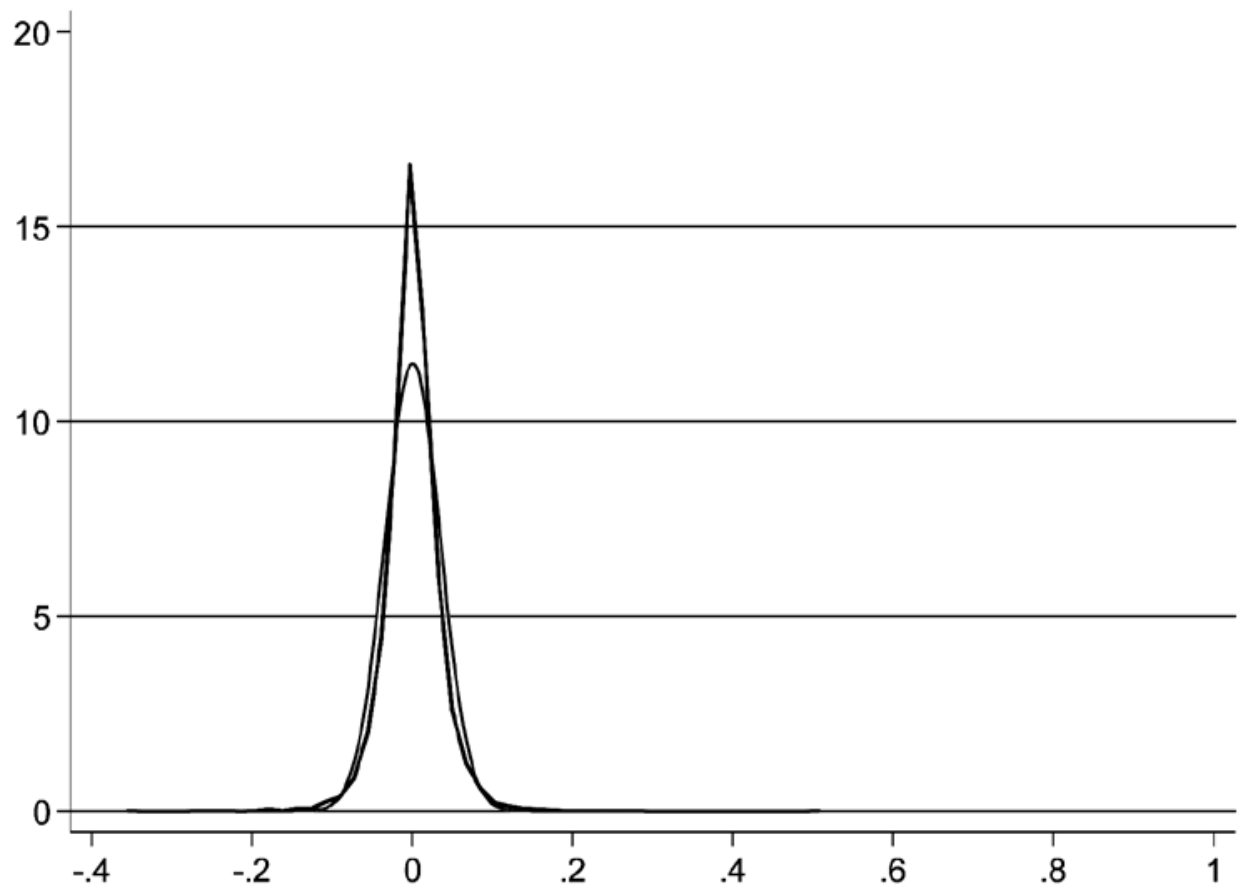

now closer to the normal distribution, the remaining extra kurtosis causes the rejection of the null hypothesis in the Jarque-Bera test. Neither of the distributions is distributed normally.

Since the measure of skewness is sensitive for the outliers in the data, we wanted to com- pute the skewness also in an alternative way. The quartile measure for skewness was developed by Bowley in 1920 and it uses quartiles in measuring the distribution skewness (Moors et al. 1996). According to this measure of skewness, both of the distributions were symmetric, 
Figure 8. Distribution of the filtered five-minute logarithmic USD/EUR returns

The returns were filtered by the Flexible Fourier Form method. Compared to the original distribution (Figure 7), the distribution of filtered returns is more symmetric and has less extra kurtosis. Both of the distributions are non-normal.

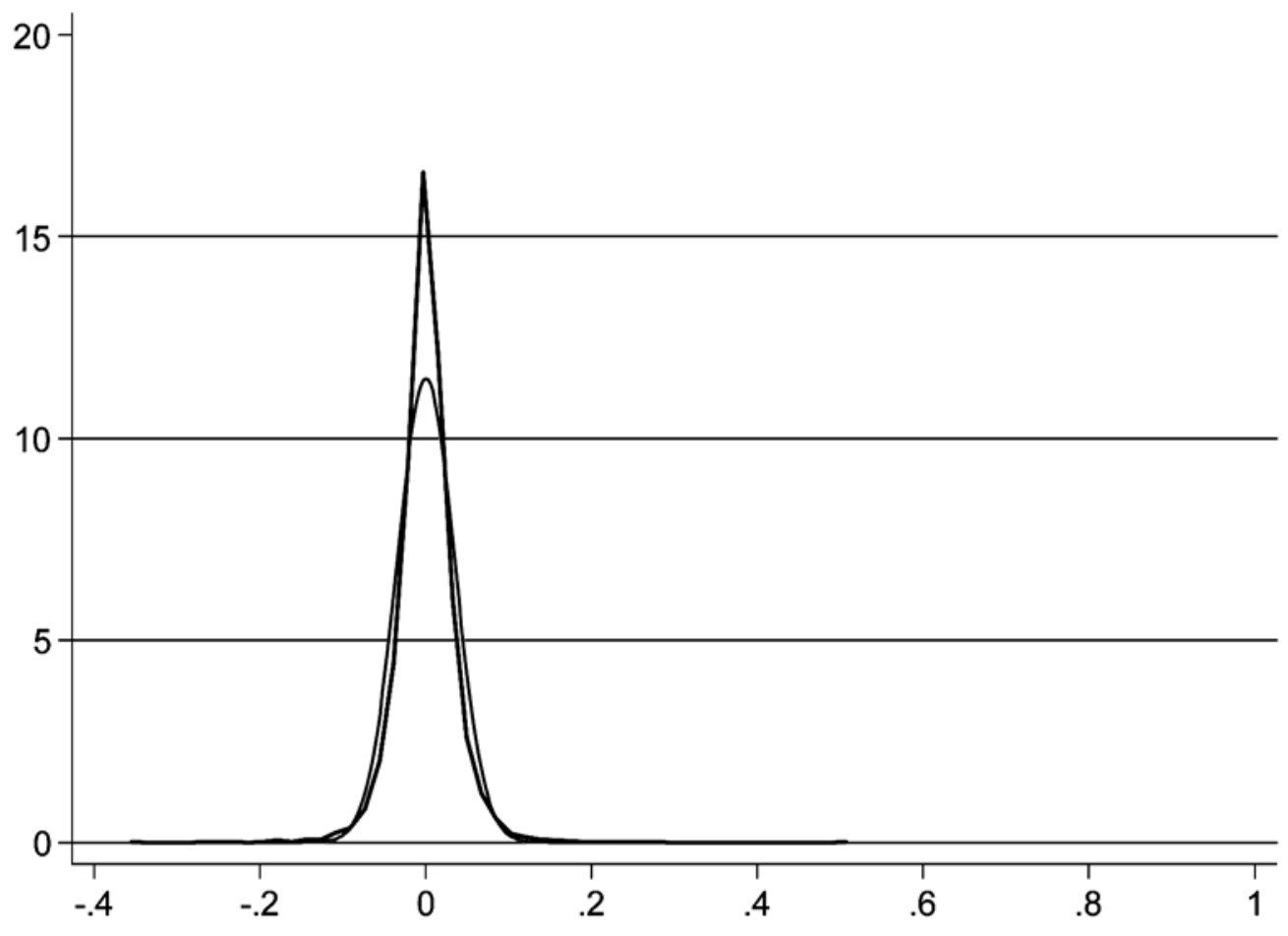

so it seems that the positive skewness is caused by a few outliers.

To get a little foretaste of the possible impact of news on exchange rate volatility, we computed the mean absolute return right before and right after the news announcement. The average absolute return five minutes before the news was $0.029 \%$ and after the news $0.043 \%$, while the average absolute return of the whole data was $0.024 \%$. So it seems then that macro announcements do increase volatility.

\subsection{Macro announcements}

The announcements were collected from the Bloomberg WECO (World Economic Calendar). These announcements are macroeconomic indicators of which announcement dates and times are known beforehand. ${ }^{8}$ Bloomberg provides

\footnotetext{
8 The complete description of the announcements can be found in Laakkonen (2004).
}

also a survey of market participants' expectations of future macro figures and the expectation of the market is taken as the median of participants' forecasts. The forecast is available only for some of the announcements. The announcements are from the USA, Germany and France. There are also announcements published by the ECB concerning the whole euro area.

There were altogether 585 announcements during the estimation period. The Bloomberg forecast was available for 379 announcements. Since many of the macro indicators are announced at the same time, the actual number of moments when the indicators were announced was a lot smaller. There were altogether 262 announcement moments in the data. The announcement moments for which there was also a forecast available totalled 172. A summary of the number of announcements is presented in Table 2.

Table 3 presents the number of announcements by country. Most of the news was an- 
Table 2.

Number of the macro announcements

Table presents the number of macro announcements from the USA, France, Germany and ECB during the period 28.10.2003-20.1.2004 collected from Bloomberg World Economic Calendar.

\begin{tabular}{lc}
\hline & Observations \\
\hline All announcements & 585 \\
Announcements with forecast & 379 \\
Announcement moments (many of the & \\
figures are announced at the same time) & 262 \\
Announcement moments with a forecast & 172 \\
$\begin{array}{l}\text { Moments when more then one macro } \\
\text { indicator is announced }\end{array}$ & 149 \\
\hline
\end{tabular}

Table 3.

Number of the macro announcements by country Table presents the number of macro announcements from the USA, France, Germany and ECB by country/area during the period 28.10.2003-20.1.2004 collected from the Bloomberg World Economic Calendar.

\begin{tabular}{lc}
\hline & Observations \\
\hline USA & 165 \\
Germany & 158 \\
France & 88 \\
ECB & 174 \\
Altogether & 585 \\
\hline
\end{tabular}

nounced by the ECB concerning the macro indicators for the whole euro area. The ECB announced 174 macro indicators during the estimation period. 165 announcements concerned the US economy, and the number of announcements from Germany and France were 158 and 88 , respectively.

The announcements were then divided into groups in order to test different hypotheses. Unfortunately we were not able to study the impact of different news separately, since we would have had too few observations for each announcement type. Instead, we wanted to examine the possible asymmetries between different groups of news. We tested five hypotheses with five models.

The studied questions were:

1. Do macro announcements increase volatility?

2. Do "no-news" announcements increase volatility?
Table 4.

Number of the announcements in the different news categories

Table presents the number of announcements in the different news categories used in testing the five different hypotheses with five models. In the Model 1, the impact of All news is examined, including those who do not have a forecast available. Model 2 compares the news whose forecast equals the announced figure (No-news) to the other news (Surprise-news). Model 3 studies the impact of news by country while Model 4 compares the impact of Positive and Negative news. Model 5 examines the differences between the Consistent news and Conflicting news. The consistent news consists all the moments that only either positive or negative news was published while the conflicting news contains the moments that conflicting news was published, i.e. both positive and negative news arrived to the markets.

\begin{tabular}{llc}
\hline Model & Category & News Items \\
\hline 1 & All news & 262 \\
2 & Surprise-news & 243 \\
& No-news & 19 \\
3 & USA & 74 \\
& ECB & 72 \\
& Germany & 72 \\
4 & France & 44 \\
& Positive & 61 \\
5 & Negative & 61 \\
& Consistent & 141 \\
& Conflicting & 31 \\
\hline
\end{tabular}

3. Do announcements from Europe and the USA have different effects?

4. Do the negative and positive news affect volatility differently?

5. Do conflicting and consistent news affect volatility differently?

Table 4 summarizes the number of news items in different announcement categories. In Model 1 we studied the impact of news in general. Therefore All news contains all the moments at which there was a macro announcement, whether there has been a forecast available or not.

According to the definition of news, the news should be something surprising. Usually the difference of the announced figure and the market forecast has been considered as the actual new information that causes volatility. Therefore, in Model 2 we examined the effect of the news whose market forecast equals the announced figure, the so called No-news. Surprise-news 
contains all the news except the news the forecast of which equals the announcement.

In Model 3 we examined the impact of news by country. USA, ECB, Germany and France contain the announcements from these countries. Model 4 compared the differences of the news impact between the Positive and Negative news. The news is positive when the market forecast is smaller than the announced figure, i.e. the news was underestimated. The negative news on the other hand means that the market agents had overestimated the macroeconomic news, and the announced figure was smaller than the forecast.

The problem with comparing for the impact of positive and negative news is that it is common for several macro indicators to be announced simultaneously. If some of them are positive and some of them are negative, this gives conflicting indications on future developments for the investors. According to the Damodaran model (1985), investors react to news in different ways depending on how they think the information affects the future payoff of their asset and how big their personal forecast errors were, i.e. how big a surprise the information was for them. Therefore, the last model examined the difference between the Consistent and Conflicting news. The announcements were divided into two groups: the first contained all the moments when the announced news was consistent, i.e. it was either positive or negative and the second contained all the news moments which gave conflicting information on the state of the economy, i.e. both kinds of news, the positive and the negative, were announced at the same time.

It has been reported that the news impact lasts from an hour to two hours (For example Bollerslev et al. 2000). To be able to examine the longer impacts of news, we computed the average absolute returns during four hours following the news announcement. We calculated the average return for the different groups of news to be able to see if there are differences in the magnitude and the length of the impact between different news groups. As can be seen from Figure 9, there are indeed some differences in the magnitude of the impact between different news groups, but it seems that the im- pact of all groups of news decays back to the average level of volatility approximately after two hours. Therefore, although there seems to be evidence also for longer news impacts, we decided to restrict the news impact to the last two hours.

The news was included to the FFF model by using the indicator variables $\sum_{k=1}^{D} \lambda_{k} I_{k}$. Following the method of Bollerslev et al. (2000), we estimated the decay structure of the volatility response pattern (Figure 10) using a third order polynomial $\gamma(i)$ (equation 3), which captures the average decay structure quite well and forces the impact to zero after two hours. Figure 10 graphs the average news response and the estimated news response. So, when the news is announced, the indicator variable $I_{k}$ gets the value of $\gamma(i)$ in the first 25 intervals after the announcement and zero otherwise. The impact of news on volatility can then be calculated with equation 4 for every 25 intervals separately.

$$
\begin{aligned}
\gamma(i) & =0.023\left(1-(i / 25)^{3}\right)-0.004\left(1-(i / 25)^{2}\right) \cdot i \\
& +0.0003(1-(i / 25)) \cdot i^{2}, i=1,2, \ldots, 25
\end{aligned}
$$

(4) $\mathrm{M}_{\mathrm{k}}(\mathrm{i})=\exp \left(\frac{\lambda_{\mathrm{k}} \cdot \gamma(\mathrm{i})}{2}\right)-1$

The longer dependencies of news could certainly have been studied also for example with lag dummies. However, the benefit of this polynomial method is, as Bollerslev et al. (2000) state, that it fixes the problem of having only a few announcement observations and it is not so sensitive to the inherent noise in the return process. One advantage of this approach is that compared to lag dummies, we now only need one news variable for each news group. When studying the effect of news during two hours after the announcement we would have needed 24 (two hours is 24 five minute intervals) news variables for every news group. Totaling 264 
Figure 9. Mean absolute returns following the macroeconomic news

Figure presents the effect of the different groups of macro news on USD/EUR volatility during four hours after news announcement. The line of mean absolute return graphs the mean absolute return of the whole data set.

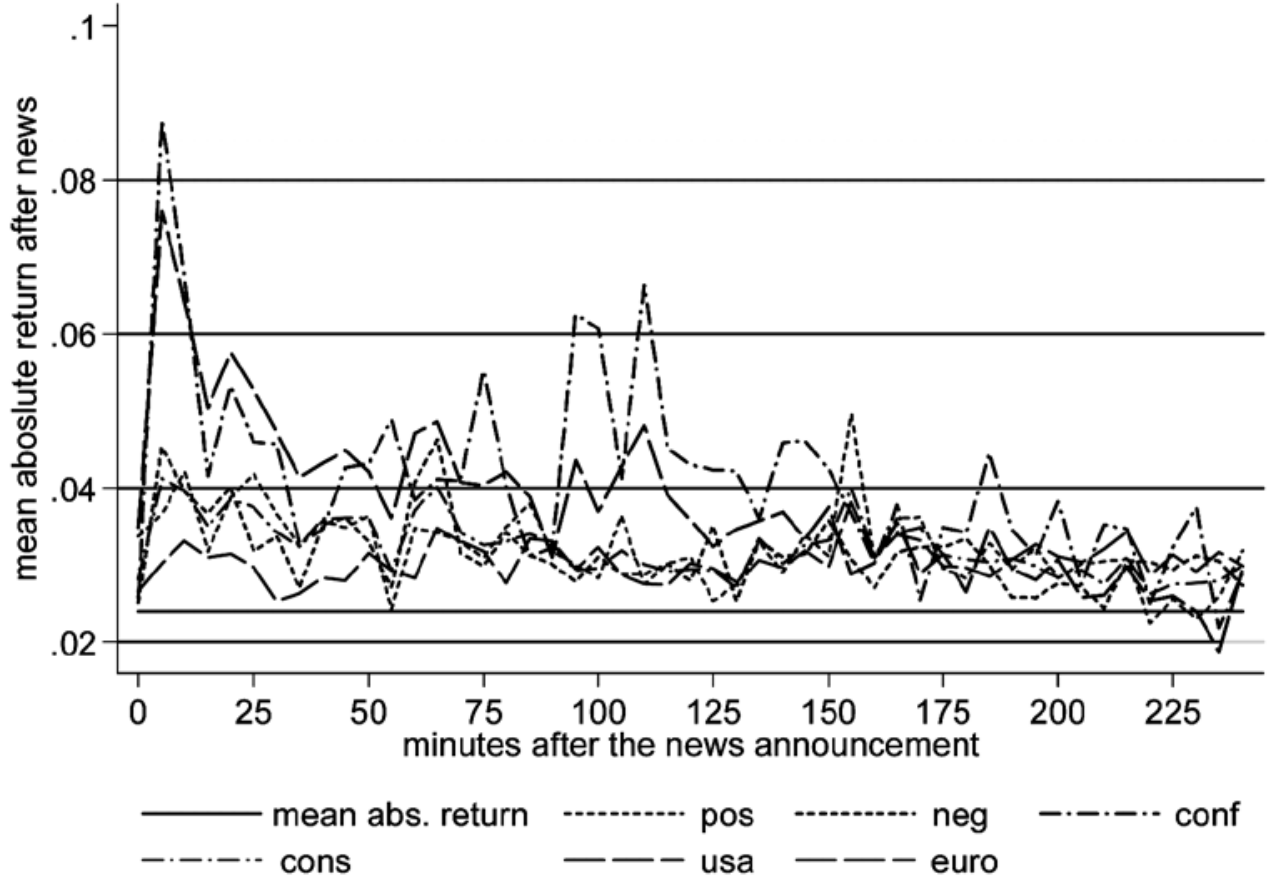

Figure 10. Average news impact pattern and the estimated decay structure

The decay structure of the news impact was estimated by using the third order polynomial $\gamma(i)$.

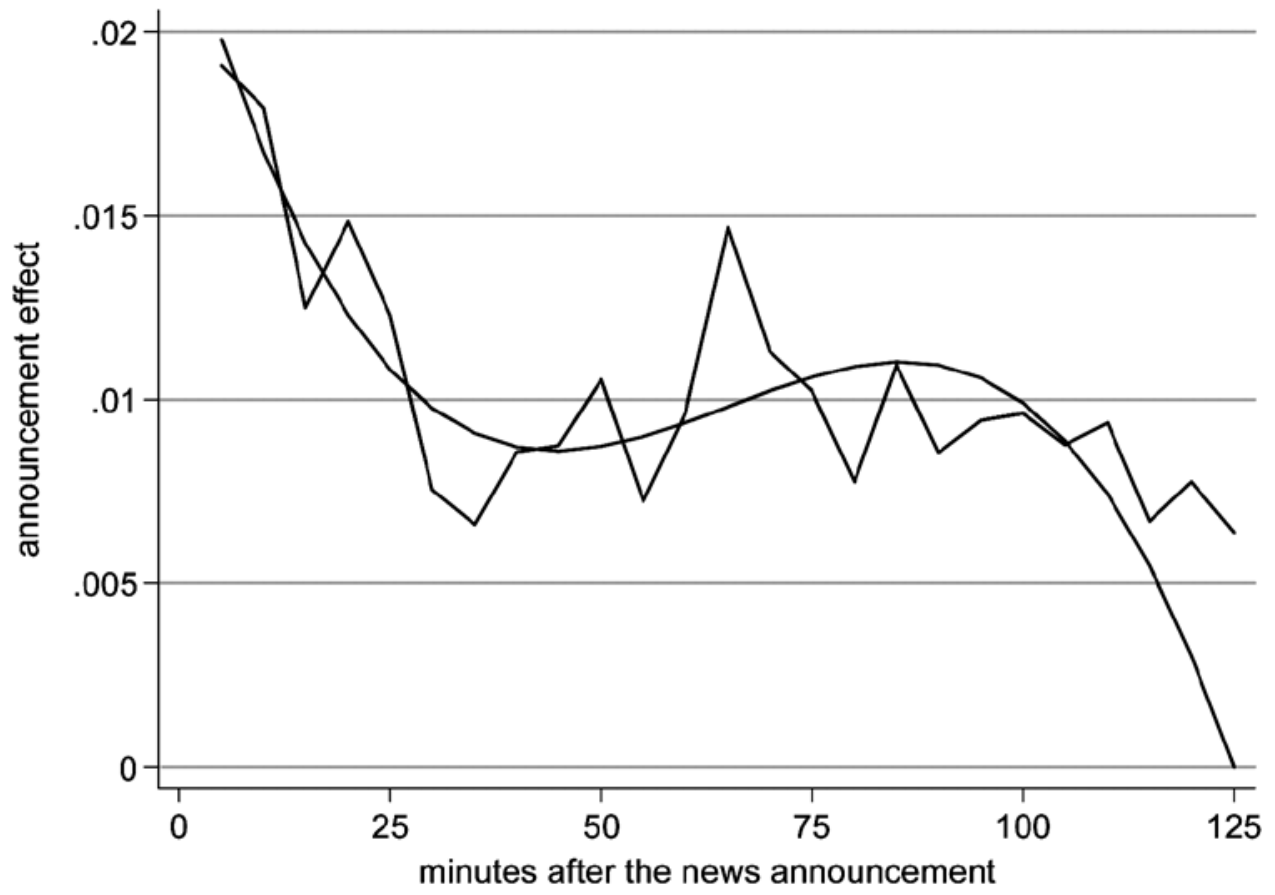


Table 5.

Estimation results

Table presents the results, where the impact of macroeconomic news on USD/EUR 5-minute frequency returns was examined with five different FFF-models (See details from Table 4). The figures in the parenthesis are the t-values computed by using the Newey-West standard errors (288 lags). The coefficients with bold font are significant at the five percent significance level. The last column presents the impact of news computed for the first 5-minute interval with equation 4.

\begin{tabular}{|c|c|c|c|c|c|c|}
\hline Variable $k$ & Model 1 & Model 2 & Model 3 & Model 4 & Model 5 & Impact $M_{k}$ \\
\hline All news & $\begin{array}{c}\mathbf{3 4 . 6 3} \\
(4.34)\end{array}$ & - & - & - & - & 0.41 \\
\hline Surprise-News & - & $\begin{array}{l}\text { 31.06 } \\
(3.90)\end{array}$ & - & - & - & 0.36 \\
\hline No-News & - & $\begin{array}{c}\mathbf{5 0 . 7 2} \\
(2.91)\end{array}$ & - & - & - & 0.65 \\
\hline USA & - & - & $\begin{array}{c}\mathbf{6 5 . 7 5} \\
(4.80)\end{array}$ & - & - & 0.92 \\
\hline ECB & - & - & $\begin{array}{c}7.45 \\
(0.72)\end{array}$ & - & - & 0.08 \\
\hline Germany & - & - & $\begin{array}{l}10.20 \\
(0.99)\end{array}$ & - & - & 0.11 \\
\hline France & - & - & $\begin{array}{l}10.50 \\
(0.76)\end{array}$ & - & - & 0.11 \\
\hline Positive & - & - & - & $\begin{array}{l}16.80 \\
(1.53)\end{array}$ & - & 0.18 \\
\hline Negative & - & - & - & $\begin{array}{c}\mathbf{2 0 . 3 0} \\
(2.06)\end{array}$ & - & 0.22 \\
\hline Consistent & - & - & - & - & $\begin{array}{c}\mathbf{2 9 . 0 3} \\
(3.56)\end{array}$ & 0.33 \\
\hline Conflicting & - & - & - & - & $\begin{array}{c}\mathbf{4 5 . 8 0} \\
(3.52)\end{array}$ & 0.57 \\
\hline
\end{tabular}

news variables when studying 11 different news group. ${ }^{9}$

\section{The results}

The news was included to the model with indicator variables, and the estimation results of the five models are presented in Table 5. The first column describes the news groups included to the model. The next five columns present the results from the five models. The figures in the parenthesis are the t-values that have been computed by using the Newey-West robust standard

9 The impact of news was studied also by using the lag dummies. The results were very similar, the same groups of news were significant and the differences in the magnitude of the news impact between different news groups remained the same. The estimation results are available from the author upon request. errors (by using 288 lags). The last column presents the impact of the news to volatility, which has been calculated with the equation 4 . We have only calculated the instant impact of the news for all news groups $M_{k}(1)$, but the impact on later intervals can be calculated using $\gamma(i)$ and the coefficient $\lambda_{k}$. The impact dynamics of the different news groups are presented in Figure 11.

\subsection{All news and No-news versus Surprise- news}

In Model 1 all the news are included in the model assuming there are no asymmetries between different news groups. The coefficient of the variable All news is highly statistically significant, so the results suggest that the macro news in general do increase the volatility. When no asymmetries are assumed, the news causes a 
Figure 11. Estimated news impacts between different news groups

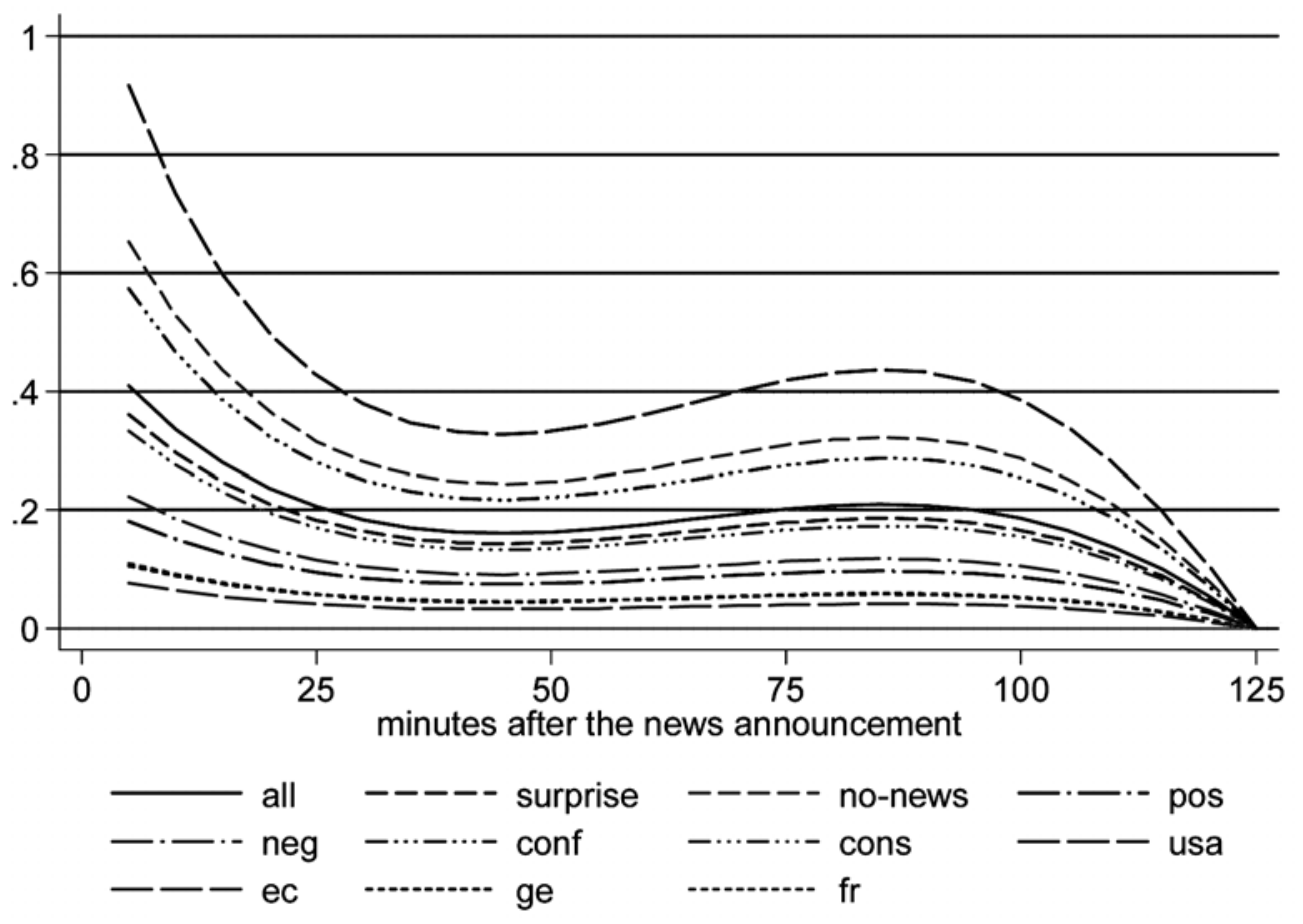

jump of $41 \%$ to the volatility right after the news announcement.

Model 2 examined the impact of announcements that did not surprise the market, since the announcement equalled the market forecast. The results indicate that also this kind of $\mathrm{No}$ news has a strong impact on volatility. The coefficient is even higher than the coefficient of the variable Surprise-news that contains all the "surprising" news. While the surprising news cause a $36 \%$ jump in the volatility, the no-news cause $65 \%$ jump to volatility right after the announcement. One explanation for this result could be that the volume of trade and therefore also volatility is lower before the news announcements, since the agents want to wait for the figures to be announced before trading. After the announcement, the volume of trade increases whether or not the announcement surprised the markets. Another explanation for no-news increasing the volatility is the fact that even though the announcement was not surprising, this doesn't necessarily mean that the news was not bad (or good). For example the Euro- pean central bank announcement of not decreasing the interest rates might be expected but not hoped.

\subsection{The impact of the US, German, France and euro-area news}

The results of Model 3 where the impact was studied by country suggest that only the news from the USA increase volatility significantly. None of coefficients of news variables from $\mathrm{Eu}-$ rope were significantly positive. While the news from the USA cause a $90 \%$ jump to volatility, the European news cause only about $10 \%$ increase.

Also other studies have found US macro news to have a bigger impact than European news (for example, Andersen et al. 2003). One reason for this is the regularity of macro announcements in the USA compared to the ones from Europe. The other result from the previous studies has been that the significant announcements from the USA are the real economy indicators (especially the unemployment report), while the 
most significant European news comes from monetary policy.

The results might also be explained by the state of the economy in the USA and Europe during the estimation period. The movement of the USD/EUR exchange rate was quite interesting during the estimation period (28 October 2003 to 20 January 2004) considering the state of the economy in these countries. Economic growth in the US was very strong; in the third quarter of 2003 the annual growth was as high as eight percent. The increasing economic growth came from an expansionary economic policy. The growth was achieved through tax reductions and increased public expenditure due to the war in Iraq. Also the monetary policy of the Fed was more expansionary than the monetary policy of the ECB: the Fed interest rate was as low as one percent, and it was not raised even though economic growth had been strong for quite a long time. Although the growth in the US was strong, it did not seem to be sustainable. Households started to be in debt and even when US competitiveness compared to Europe had improved, the foreign trade deficit did not decrease.

The economy in Europe was recovering little by little. Still, the growth was not anything like the growth in the US. In the year 2003 European growth slowed down and was eventually only 0.7 percent. There seems to have been conditions for faster growth, however. The interest rates were not too high and the financial position of the households was relatively good compared to the position of households in the US. The increase of growth was restrained partly by the strengthening euro, which caused the weakening competitiveness of the euro area.

The fiscal policy of the euro area was not strict about stability and growth restrictions. The budget deficits of EMU countries increased, since the policy-makers wanted to avoid slowing down growth by reducing public expenditures. The economic indicators looked promising. The means of the indicators (industry, construction, retail trade, consumer confidence and private services) in December 2003 and February 2004 were higher than the means of the earlier three-month period. Nonetheless the recov- ery of the European economy was still lower than expected.

All in all, compared to the situation in the USA, there were no very surprising elements in the European economy. Although the economic situation seemed to be good in the USA, it increased uncertainty in the markets (The Research Institute of the Finnish Economy, Suhdanne 1/2004; Labour Institute for Economic Research, Talousennuste, March 2004).

\subsection{Positive vs. negative news and consistent vs. conflicting news}

The differences of the impact of the news between positive and negative news was studied in Model 4. Only the coefficient of negative news is statistically greater than zero. Therefore the result of negative news having the greater impact is reconfirmed in this study. However, it is interesting that both coefficients are quite low. Negative news causes only approximately $20 \%$ jump to the volatility. The answer might be found from Model 5 .

According to the results of the Model 5, conflicting news increases volatility more than consistent news. When only the instant impact of news is studied with news dummies, the difference between the coefficients is statistically significant ${ }^{10}$. When the whole impact after two hours from announcement is modelled, the difference between the coefficients is still quite large. While the consistent news cause a 33\% jump to volatility, the conflicting news cause almost a $60 \%$ jump to volatility. As the impact of positive and negative news was examined, it has to be remembered that all the announcements included in this estimation would be included in a consistent news variable. The result of examining the conflicting information may help to understand why the impact of positive and negative news seemed to be so low.

10 Value of the Wald statistics was 11.84 (p-value 0.0006) 


\section{Conclusions}

Our results suggest that the macro fundamentals and exchange rates do have a connection also in the short run: the macro economic news increase the volatility of exchange rates immediately after the announcement. We examined the impact of macroeconomic news on USD/EUR volatility with a new 5 minute frequency data set and studied the asymmetries in the impact between different groups of news.

According to our results, the news increase volatility significantly. How large the jump after the announcement is, depends on the news category. When the announcements were studied by country, only the US macro indicators were significant. Of the European macro indicators, ECB news had the weakest impact on volatility. This can be understood when the macroeconomic situation of Europe and the USA is compared during the estimation period. Although economic growth in Europe had been sluggish for some time, the monetary policy of the ECB had not been very aggressive. In contrast, economic growth in the USA during the estimation period was quite rapid, although not sustainable. Both US fiscal and monetary policy boosted growth during the estimation period. Compared to the situation in the USA, there were no very surprising elements in the European economy. Although the economic situation seemed to be good in the USA, it increased uncertainty in the markets.

This study supports the argument that the impact of negative news is stronger than the impact of positive news. According to the results negative news increase volatility more than positive news. However, the impact of positive and negative news was found to be surprisingly low. The most significant result of this study was achieved with another hypothesis. According to the resent theory of Manzan and Westerhoff (2005), even the professional traders experience difficulties when evaluating the meaning of news. When the signal of the news is not so clear it is clearly more difficult to analyze news. The hypothesis of consistent and conflicting news was tested, and according to the results, the news that give conflicting information on the state of the economy increase volatility more than the news that give consistent information. Manzan and Werterhoff (2005) suggest that central authorities should provide more reliable information about fundamentals, so that the degree of misperception might decrease.

\section{References}

Admati, A., and P. Pfleiderer (1988). "A theory of Intraday Patterns: Volume and Price Variability." Review of Financial Studies 1, 3-40.

Aggarwal R., and D. Schirm (1992). "Balance of Trade Announcements and Asset Prices: Influence on Equity Prices, Exchange Rates, and Interest Rates." Journal of International Money and Finance 11, 80-95.

Almeida A., C. Goodhart, -and R. Payne (1998). "The Effects of Macroeconomic News on High Frequency Exchange Rate Behavior." Journal of Financial and Quantitative Analysis 33, 383-408.

Andersen T., and T. Bollerslev (1997). "Intraday periodicity and volatility persistence in financial markets." Journal of empirical finance 4, 115-159.

Andersen T., and T. Bollerslev (1998). "Deutsche MarkDollar Volatility: Intraday Activity Patterns, Macroeconomic Announcements, and Longer Run Dependencies." Journal of Finance 53, 219-265.

Andersen T., T. Bollerslev, F. Diebold, and C. Vega (2003). "Micro Effects of Macro Announcements: RealTime Price discovery in Foreign Exchange." American Economic Review 93, No.1.

Barberis, N., A. Schleifer, and R. Vishny (1998). "A model of investor sentiment." Journal of Financial Economics 49, 307-343.

BIS (2005). "Triennial Central Bank Survey: Foreign exchange and derivatives market activity in 2004." Bank for International Settlements.

Bollerslev T., R. Y. Chou, and K. F. Kroner (1992). "ARCH modelling in finance." Journal of Econometrics $52,5-59$.

Bollerslev T., J. Cai, and F. M. Song (2000). "Intraday periodicity, long memory volatility, and macroeconomic announcement effects in the US Treasury bond market." Journal of Empirical Finance 7, 37-55.

Cai J., Y. Cheung, R. Lee, and M. Melvin (2001). “'Oncein-a-Generation' Yen Volatility in 1998: Fundamentals, Intervention and Order Flow." Journal of International Money and Finance 20, 327-347.

Chang Y., S. Taylor, and M. Martens (2002). "A Comparison of Seasonal Adjustment methods when forecasting Intraday Volatility." Journal of Financial Research $25,283-297$.

Chang Y., and S. Taylor (2003). "Information arrivals and intraday exchange rate volatility." International Financial Markets, Institutions and Money, 13, 85-112.

Chan Y., A. Chui, and C. Kwok (2001). "The impact of salient political and economic news on the trading activity." Pacific-Basin Finance Journal 9, 195-217.

Damodaran A. (1985). "Economic Events, Information Structure, and the Return-generating Process." Journal of Financial and Quantitative Analysis 20, No. 4.

Eddelbüttel D., and T. McCurdy (1998). "The Impact of News on Foreign Exchange Rates: Evidence from High Frequency Data." Manuscript Rotman School of Management, University of Toronto. 
Evans M., and R. Lyons (2005). "Do currency markets absorb news quickly?" Journal of International Money and Finance 24, 197-217.

Farmer D., and S. Joshi (2002). "The price dynamics of common trading strategies." Journal of Economic Behavior and Organization 49, 149-171.

Forsberg L., and E. Ghysels (2004). "Why Do Absolute Returns Predict Volatility So Well?" University of Uppsala and University of North Carolina.

Gallant R. (1981). "On the Bias in Flexible Functional Forms and an Essentially Unbiased Form: The Fourier Flexible Form." Journal of Econometrics 15, 211-45.

Goodhart C., S. Hall, S. Henry, and B. Pesaran (1993). "News Effects in a High-Frequency Model of the Sterling-Dollar Exchange Rate." Journal of Applied Econometrics 8, 1-13.

Granger C., and C-Y. Sin (1999). "Modelling the absolute returns of different stock indices: exploring the forecast ability of an alternative measure of risk." University of California, San Diego, Department of economics.
Laakkonen H. (2004). "The Impact of macroeconomic news on exchange rate volatility." Bank of Finland Discussion Paper 24/2004.

Manzan S., and F. Westerhoff (2005). "Representativeness of news and exchange rate dynamics." Journal of Economic Dynamics \& Control Vol. 29, 677-689.

Meese R. A., and K. Rogoff (1983). "Empirical exchange rate models of the seventies: do they fit out of sample?" Journal of International Economics 14, 3-24.

Melvin M., and X. Yin (2000). "Public Information Arrival, Exchange Rate Volatility and Quote Frequency." Economic Journal 110, Issue 465.

Moors J., R. Wagemakers, V. Coenen, R. Heuts, and M. Janssens (1996). "Characterizing systems of distributions by quantile measures." Statistica Neederlandica 50, 417-430.

Palkansaajien tutkimuslaitos, Talousennuste, maaliskuu 2004

Suhdanne 1/2004 ETLA 